\title{
Fixed-interval frustrative nonreward in profound
}

retardates

J. WESLEY LIBB, University of Alabama,
University, Ala. 35486

The free-operant FI schedule is proposed as an assessment technique in frustrative nonreward investigations. Three profoundly retarded adult males were reinforced with candy for FI 1 performance. When behavior stabilized, reward was omitted $25 \%$ of the time, and responding subsequent to rewarded and nonrewarded trials was compared at four equidistant points across the interval. Responding was enhanced in the first $30 \mathrm{sec}$ for all three $S$ s. For one $S$, this effect continued across the 60-sec interval, while for another $S$ the effect was evident in all but the final 15-sec segment. For the third $S$, responding decreased considerably in the final 30 sec. In general, the results are compatible with the frustrative nonreward literature. Alternative hypotheses are considered.

Nonreward of a previously rewarded response has been demonstrated to have an energizing effect on an immediately subsequent well-established response (Amsel, 1958). Compatible evidence exists for human Ss, although data for the mentally retarded are ambiguous and the frustration effect (FE) frequently of only marginal magnitude (Ryan \& Watson, 1968). With adequate definition and control of relevant variables, however, the FE has been demonstrated reliably with the mentally retarded, i.e., following nonreward of a response previously rewarded, the next response in the sequence is performed significantly more quickly and vigorously as evidenced in response latencies and pressure on a lever (Ryan \& Watson, 1968).

Several factors emerging from the literature on human Ss that create possible methodological problems are (1) the relatively short period of time during which the FE may be maximally evidenced, i.e., with greater than 10 -sec intervals between frustration and assessment of the dependent variable the effect generally vanished, (2) possible long-lasting cumulative energizing effects from frustration trials that may carry over through many trials, confounding the data and further increasing the possibility of (3) ceiling effects, i.e., the $S$ may be responding at or near his physical capacity following rewarded trials, hence increased motivation can be only marginally demonstrated. This problem seems most acute when the response to be investigated is a single relatively small piece of behavior, or a discrete trial. Finally, (4) al though the FE is presumed to dissipate gradually across time, the between-Ss design employed in previous investigations has been relatively barren in generating clear evidence.

The free-operant fixed interval (FI) schedule of reinforcement may permit the assessment of the FE across time. Additionally, since periods of low response rate are typical, a response ceiling would be less likely, and effects may be evidenced for a longer period of time.

This experiment investigates the utility of the FI in assessing FE among retarded human Ss. Of interest is the magnitude and duration of the effect. Also, this study employs more severely retarded Ss than previously reported in the literature. Although the data on retardate FI performance is somewhat limited, at least one study (Spradlin, Girardeau, \& Corte, 1965) indicate behavior similar to that of normal human Ss and lower organisms.

\section{SUBJECTS}

The Ss were three experimentally naive institutionalized profoundly retarded adult males, 20-30 years of age, from Partlow State School and Hospital, Tuscaloosa, Alabama, who were ambulatory and responsive to visual cues. These $S s$ are hereafter referred to as S-H, S-M, and S-G. S-M and S-H were on $25 \mathrm{mg}$ of Melaril, t.i.d. The other $\mathrm{S}$ was not medicated during the experiment.

\section{APPARATUS}

The experimental chamber was a sound-dampened room about $8 \mathrm{ft}$ high and $6 \mathrm{ft}$ square, with three one-way observation windows. The contingencies were programmed with electromechanical timers, steppers, and appropriate relay circuitry. The data were recorded on electromagnetic counters, running time meters, and a cumulative recorder. Programming equipment was located in a separate room. The response panel, mounted in the middle of one wall of the chamber, consisted of a small stimulus light illuminated when the interval contingency was in effect, a delivery tray, a small tray light, and a Lindsley plunger. Reinforcement consisted of automatic delivery of one M\&M candy, at which time the stimulus light was extinguished and the delivery tray light illuminated for $5 \mathrm{sec}$. The next interval was then initiated.

\section{PROCEDURE}

Plunger-pulling was shaped by a "fading-out" technique in which the E initially aided $S$ in pulling the plunger and gradually withdrew assistance on successive trials. Initially, each response was reinforced. After $S$ obtained about 20 M\&Ms without assistance, an FI contingency was introduced and gradually lengthened from about $5 \mathrm{sec}$ to $1 \mathrm{~min}$, over about 30 reinforcements. Daily sessions subsequently consisted of the delivery of 20 reinforcements. Each $S$ was run 5 to 6 days per week. The $5 \%$ stability criterion as defined by Schoenfeld, Cumming, \& Hearst (1956) was implemented. Following stable performance on the FI $1 \mathrm{~min}$, reinforcement failed on a randomized $25 \%$ of the trials, i.e., stimulus conditions accompanying reinforcement occurred, but no M\&M was delivered. Data were gathered from a total of five additional sessions. Number of responses in successive $15-\mathrm{sec}$ quarters of the interval were recorded separately following both rewarded and nonrewarded intervals. Each $S$ thus served as his own control.

\section{RESULTS AND DISCUSSION}

All Ss experienced a total of at least 15 sessions of $100 \%$ rewarded FI trials. Performance on the last six sessions was tabulated in terms of mean number of responses per successive 15-sec quarters of the interval. Responses in each of these $15-\mathrm{sec}$ segments were an increasing function of the passage of time in the interval; hence, on the average, each $S$ responded to the FI with a somewhat typical FI scallop. General inspection of cumulative records was consistent with this mean figure, though considerable variability persisted.

The data reported in Table 1 were obtained from the five sessions of the experimental condition. Mean number of responses for each $S$ per successive quarters of the interval following both rewarded and nonrewarded trials is presented. A total of 25 trials per $S$ served as the basis for responses subsequent to nonreward, while 75 trials were included for responses following rewarded trials. During both the first and second 15-sec intervals following nonreward, a dramatic increase in responding is evidenced for all three Ss. For two of the three Ss similar enchancement of responding following nonreward when compared with reward was evidenced in the third 15 -sec interval, or 30-45 sec after nonreward. In this same segment, for $S-G$ the number of responses following nonreward dropped off slightly. In the final 15 -sec segment, or $45-60 \mathrm{sec}$ after nonreward, only $\mathrm{S}-\mathrm{H}$ continued the increased response rate. Number of responses was essentially the same 
Table 1

Mean Responses Per Interval and Successive Quarter of Interval Subsequent to Rewarded and Nonrewarded Trials for All Three Ss Based on Five Experimental Sessions

\begin{tabular}{|c|c|c|c|c|c|c|}
\hline & & \multicolumn{4}{|c|}{ Interval Segment } & \multirow{2}{*}{$\begin{array}{c}\text { Interval } \\
\text { Total }\end{array}$} \\
\hline & & 1 & 2 & 3 & 4 & \\
\hline$S-M$ & $\begin{array}{l}\text { Reward } \\
\text { Nonreward }\end{array}$ & $\begin{array}{r}.75 \\
2.92\end{array}$ & $\begin{array}{l}1.53 \\
3.24\end{array}$ & $\begin{array}{l}2.48 \\
3.40\end{array}$ & $\begin{array}{l}4.25 \\
4.20\end{array}$ & $\begin{array}{r}9.01 \\
13.76\end{array}$ \\
\hline $\mathbf{S}-\mathbf{H}$ & $\begin{array}{l}\text { Reward } \\
\text { Nonreward }\end{array}$ & $\begin{array}{r}.08 \\
2.36\end{array}$ & $\begin{array}{r}.16 \\
2.64\end{array}$ & $\begin{array}{r}.50 \\
1.76\end{array}$ & $\begin{array}{l}1.95 \\
3.56\end{array}$ & $\begin{array}{r}2.69 \\
10.32\end{array}$ \\
\hline$S-G$ & $\begin{array}{l}\text { Reward } \\
\text { Nonreward }\end{array}$ & $\begin{array}{r}.92 \\
1.30\end{array}$ & $\begin{array}{l}1.68 \\
2.00 \\
\end{array}$ & $\begin{array}{l}2.10 \\
1.56 \\
\end{array}$ & $\begin{array}{l}3.17 \\
2.50\end{array}$ & $\begin{array}{l}7.87 \\
7.36 \\
\end{array}$ \\
\hline
\end{tabular}

following rewarded and nonrewarded trials for S-M, while for $S-G$ the responses following reward actually exceeded responses following nonreward. In terms of total number of responses across the 1 -min interval, $\mathrm{S}-\mathrm{H}$ and $\mathrm{S}-\mathrm{M}$ showed a general increment in responding ( $283 \%$ and $53 \%$, respectively), while S-G showed no overall effect, the increase early in the interval being balanced by a subsequent decrement in the later half of the interval for this $S$. Combining the percentage increases for all three Ss, an overall increase of $110 \%$ is seen following nonrewarded trials.

The behavior of all three Ss in the first $30 \mathrm{sec}$ after nonreward is consistent with frustration theory predicting response enhancement following nonreward. These findings are consistent with similar FI operant studies with animals (Staddon \& Innis, 1966). Davenport \& Thompson (1965) also found similar response enhancement following nonreward in a free-operant FR procedure. As in previous studies with children (Ryan \& Watson, 1968), the immediate effect is of greatest magnitude. Interestingly, the effect continued for a greater length of time than the usual 10-sec period demonstrated in other work. Such discrepancies are likely a function of the schedule and are consistent with the prediction that, where uncontaminated with response ceilings, an energizing effect of greater than $10-\mathrm{sec}$ duration might be evidenced. These findings extend frustration findings to a profoundly retarded population.

It may be argued that the effects are explicable purely on the grounds that following rewarded trials $S$ had an M\&M to manipulate, while on frustrated trials he did not, hence he manipulated the plunger. Observational data indicated that all Ss immediately ate the $M \& M$, having it in mouth before the end of the 5 -sec reinforcement event. The suppression effect of rewarded trials has been discussed by Wagner (1959) and FE demonstrated with such effects well-controlled.

That the FE was evident in the later quarter of the interval for only one of three Ss may suggest its dissipation. Since responding in the FI is also an increasing change at reinforcement was dramatic and significantly defined the reinforcement event; however, this analysis remains relevant.

While the FI offers interesting possibilities for frustration research, many questions remain unanswered. Studies in process by the author relate to the issues as defined above.

\section{REFERENCES}

AMSEL, A. The role of frustrative non-reward in noncontinuous reward situations. Psychological Bulletin, 1958, 55, 102-119.

function of time since rcinforcement and responding following rewarded trials was relatively high at this point, the final quarter may suffer from the response ceiling problem.

Another question arising from this investigation involves the similarity of nonreward conditions as defined in this experiment and the typical secondary reinforcement situation. Stimuli occurring on nonrewarded trials were the same as those paired with reinforcement on rewarded trials, hence nonreward consisted of secondary reinforcement. That most of the frustration literature involves this same similarity has been noted by Longstreth (1966). With such considerations in mind, an incentive motivation interpretation is also relevant to the data.

A final problem involves the special characteristics of the interval schedule. Time since reinforcement is a significant variable related to response probability in the interval schedule, hence increased rate of responding following nonreward may in fact be a function of time since reward. Staddon (1967) suggests a similar argument for the animal FI data. The stimulus

A ENPORT, J. W., \& THOMPSON, C. I. The Amsel frustration effect in monkeys. Psychonomic Science, 1965, 3, 481-482.

LONGSTRETH, L. E. Frustration and secondary reinforcement concepts as applied to human instrumental conditioning and extinction. Psychological Monographs: General \& Applied, $1966,80,29$.

RYAN, T. J., \& WATSON, P. Frustrative non-reward theory applied to children's behavior. Psychological Bulletin, 1968, 69, 111-125.

SCHOENFELD, W. N., CUMMING, W. W., \& HEARST, E. On the classification of reinforcement schedules. Proceedings of the National Academy of Sciences, 1956, 42, 563-570. SPRADLIN, J. E., GIRARDEAU, F. L., \& CORTE, E. Fixed ratio and fixed interval behavior of severely and profoundly retarded subjects. Journal of Experimental Child Psychology, 1965, 2, 340-353.

STADDON, J. E. R. Attention and temporal discrimination: Factors controlling responding under a cyclic-interval schedule. Journal of the Experimental Analysis of Behavior, 1967, 10, 349-359.

STADDON, J. E. R., \& INNIS, N. K. An effect analogous to "frustration" on interval reinforcement schedules. Psychonomic Science, 1966, 4, 287-288.

WAGNER, A. $R$. The role of reinforcement and non-reinforcement in an apparent frustration effect. Journal of Experimental Psychology, $1959,57,130-136$

\section{Instructions to ignore a stimulus and the GSR}

\section{ROBERT J. KOHLENBERG, University of notion that effects due to signal value are Washington, Seattle, Wash. 98105 \\ larger than effects due to demand characteristics.}

According to research on the orienting reflex, the instructions to ignore a stimulus would increase the signal value and result in an increased GSR elicited by that stimulus. A decreased GSR, however, would be expected due to the effect of demand characteristics of the experiment. As a test of these opposing effects, Ss were presented three different tones and instructed to ignore one of them. The results indicate that the GSR is enhanced for the ignored stimulus and support the
This study is concerned with the instruction to "ignore" a stimulus on the elicited GSR. Such effects would be important in the interpretation of studies in which the experimental effect is measured by reduced GSRs if a $S$ could produce a reduced GSR voluntarily as a result of $E$ hypothesis (Rosenthal, 1963) or demand characteristics (Orne, 1962).

The GSR is a frequently employed dependent variable in a wide range of 